\title{
The long-term health effects of attending a selective school: a natural experiment
}

\author{
Jessica Butler ${ }^{1} \mathbb{D}$, Corri Black${ }^{1}$, Peter Craig $^{2}$, Chris Dibben ${ }^{3}$, Ruth Dundas ${ }^{2}$, Michelle Hilton Boon², \\ Marjorie Johnston ${ }^{1}$ and Frank Popham ${ }^{2 *}$
}

\begin{abstract}
Background: Education is widely associated with better physical and mental health, but isolating its causal effect is difficult because education is linked with many socioeconomic advantages. One way to isolate education's effect is to consider environments where similar students are assigned to different educational experiences based on objective criteria. Here we measure the health effects of assignment to selective schooling based on test score, a widely debated educational policy.

Methods: In 1960s Britain, children were assigned to secondary schools via a test taken at age 11. We used regression discontinuity analysis to measure health differences in 5039 people who were separated into selective and non-selective schools this way. We measured selective schooling's effect on six outcomes: mid-life self-reports of health, mental health, and life limitation due to health, as well as chronic disease burden derived from hospital records in mid-life and later life, and the likelihood of dying prematurely. The analysis plan was accepted as a registered report while we were blind to the health outcome data.
\end{abstract}

Results: Effect estimates for selective schooling were as follows: self-reported health, 0.1 worse on a 4-point scale $(95 \% \mathrm{Cl}-0.2$ to 0$)$; mental health, 0.2 worse on a 16 -point scale ( -0.5 to 0.1$)$; likelihood of life limitation due to health, 5 percentage points higher ( -1 to 10$)$; mid-life chronic disease diagnoses, 3 fewer/100 people $(-9$ to +4$)$; late-life chronic disease diagnoses, 9 more/100 people $(-3$ to +20$)$; and risk of dying before age 60 , no difference ( -2 to 3 percentage points). Extensive sensitivity analyses gave estimates consistent with these results. In summary, effects ranged from $0.10-0.15$ standard deviations worse for self-reported health, and from 0.02 standard deviations better to 0.07 worse for records-derived health. However, they were too imprecise to allow the conclusion that selective schooling was detrimental.

Conclusions: We found that people who attended selective secondary school had more advantaged economic backgrounds, higher IQs, higher likelihood of getting a university degree, and better health. However, we did not find that selective schooling itself improved health. This lack of a positive influence of selective secondary schooling on health was consistent despite varying a wide range of model assumptions.

\section{Background}

Education is associated with physical and mental health and life expectancy in countries around the world, and the role of education in improving health is a focus of

\footnotetext{
* Correspondence: Frank.Popham@glasgow.ac.uk

${ }^{2}$ MRC/CSO Social and Public Health Sciences Unit, University of Glasgow, 200 Renfield Street, Glasgow G2 3AX, UK

Full list of author information is available at the end of the article
}

diverse research and global policy [1-6]. However, there is vigorous debate about the causal effects of educational reforms. Because children from socio-economically advantaged families are more likely to attend betterresourced schools, be educated longer, and gain more qualificatio ns, the association between education and health may simply reflect background advantages rather than effects of educational policy itself $[4,7-9]$.

(c) The Author(s). 2020 Open Access This article is licensed under a Creative Commons Attribution 4.0 International License, which permits use, sharing, adaptation, distribution and reproduction in any medium or format, as long as you give appropriate credit to the original author(s) and the source, provide a link to the Creative Commons licence, and indicate if changes were made. The images or other third party material in this article are included in the article's Creative Commons licence, unless indicated otherwise in a credit line to the material. If material is not included in the article's Creative Commons licence and your intended use is not permitted by statutory regulation or exceeds the permitted use, you will need to obtain permission directly from the copyright holder. To view a copy of this licence, visit http://creativecommons.org/licenses/by/4.0/. The Creative Commons Public Domain Dedication waiver (http://creativecommons.org/publicdomain/zero/1.0/) applies to the data made available in this article, unless otherwise stated in a credit line to the data. 
Studies seeking to identify the true causal effects of education on health have focused on evaluating increases in length of schooling. They take advantage of policy decisions that create "natural experiments", or environments that mimic the conditions of a randomised trial [10]. One such natural experiment is a nationwide increase in the age at which a child may legally leave school, which allows the comparison of the health of the cohorts just before and just after the policy was implemented. Analyses of these natural experiments across multiple countries have shown that length of compulsory education causes small but significant reductions in mortality, smoking, and obesity [11-14].

The long-term effects of other educational reforms have received less attention. Here we consider the policy of stratifying students based on their academic ability, referred to as selective schooling. Historically, most developed nations stratified students by ability either into separate schools or classes, but since the 1960s many countries moved to less stratification $[15,16]$. Recently, however, the policy has come back into debate, and across OECD nations, there have been reforms both towards a more stratified system and away from it [17]. In the UK, the educational system moved from selective to comprehensive more than 40 years ago $[18,19]$, but the present UK government has pledged a return to a stratified system in an effort to reduce the achievement gap between children of different socioeconomic circumstances [20].

Previous analyses of selective schooling's effects have focused on its impact on educational trajectories and long-term economic outcomes [21-24]. In contrast, selective schooling's effects on health have been less well explored. The mechanisms by which selective schooling may change health are proposed to be both direct, via health literacy, as well as indirect via changes in prosperity, status, and control [25-27]. However, while studies have demonstrated an association between selective schooling and health, the results have been shown to be subject to confounding. Recent work has attempted to model the association more robustly by controlling for a wide variety of covariates and matching exposed and unexposed individuals [28-30]. However, in addition to the potential of residual confounding, these studies evaluated only self-reported health measures derived from participant survey. The results are hampered both by surveys only through mid-life and by high attrition over time leaving a non-representative population.

Here we take advantage of a natural experiment in school assignment that occurred in Britain in the 1960s, as well as the data sharing policy of the National Health Service of Scotland to evaluate the long-term causal effects of selective schooling on health. Our study population is 8087 people who were assigned to selective or non-selective secondary school based on their performance on an exam taken at age 11. They are part of the Aberdeen Children of the 1950s, a long-running birth cohort which holds extensive data on participants from across their lives [31,32]. As this population was one of the last to be assigned to school via exam, and as they are now over 60, they provide an excellent opportunity to evaluate long-term health effects. We show that a regression discontinuity design which alleviates the bias due to residual confounding is appropriate for estimating the effect on health of attending a selective secondary school. We consider a wider range of outcomes than previous studies, including self-reported physical health and mental health, diagnoses of 30 chronic conditions from hospital records, and premature death. We consider health at two periods: when participants were in middle age and early old age.

\section{Methods}

\section{Study design}

A detailed study design was pre-registered and accepted by BMC Medicine as a registered report after peer review [33]. We were blind to participant outcomes before study acceptance.

This analysis uses a regression discontinuity design to investigate the effect of selective secondary schooling on health $[34,35]$. In such a design, allocation to an exposure depends on the value of a continuous variable (the forcing variable). In this study, assignment to selective schooling depended on an exam score at age 11.

The design assumes that if there were no treatment effect, there would be a smooth relationship between the forcing variable and the outcome. In this study, if selective secondary schooling has no effect on health, the association of health outcomes will be smooth across exam scores. However, if there is a discontinuity in this smooth relationship at the forcing variable cut-point (i.e. if health outcomes change suddenly in people with scores close to the cut-point), the effect can be attributed to selective schooling. We designed the analysis based on recommendations in Cattaneo, Idrobo and Titiunik [36].

\section{Data sources}

We used data previously collected by the Aberdeen Children of the 1950s birth cohort study linked to NHS Scotland routinely collected hospital admissions data.

\section{Exposure}

In the UK in the 1960s, there were two types of state-run secondary schools: junior secondary (called secondary modern schools in England) designed to prepare students for training and work, and senior secondary (grammar 
schools in England) designed to prepare students for further education at university and professional careers [37].

Students were allocated to secondary school based on their performance on a series of tests taken in the final year of primary school, referred to as the 11+ exam [19]. For Aberdeen Children of the 1950s participants, those with 11+ exam scores below 540 were assigned to junior secondary schools; those with scores at or above 560 were assigned to senior secondary schools; and those in between were considered individually [38].

\section{Outcomes}

We considered the following six measures as outcomes:

1) Overall health score (self-reported in 2001)

2) Mental health score (self-reported in 2001)

3) Presence of limitation due to health problems (selfreported in 2001)

4) Number of chronic diseases (from hospital records 1997-2001)

5) Number of chronic diseases (from hospital records 2011-2015)

6) Risk of death by age 60 (from national death records)

The first three outcomes were collected by postal survey of the cohort in 2001 when they were between 46 and 51 years old [32].

The two chronic disease burden outcomes were derived from hospital and mental health admission records (NHS Scotland Information Service Division datasets SMR01 and SMR04 [39]). Diagnoses of any of the chronic conditions validated by Tonelli [40] were counted. Two 5-year windows were analysed, the first corresponding to the participants' mid-life (46-51 years old) at the time as when they were surveyed on their health, and the second corresponding to early old age (60-65 years old).

Date of death is held by the Aberdeen Children of the 1950s study and is updated quarterly from the death certificates at National Records of Scotland [32].

In addition to the above health outcomes, we also report analysis of the known positive control outcome of probability of completing a higher degree [23].

\section{Population exclusions}

There are 12,148 people in total in the Aberdeen Children of the 1950s study-the population is all the children born in Aberdeen between 1950 and 1955 who attended primary school there. The $11+$ exam and assignment procedure were changed the year the youngest students in the Aberdeen Children of the 1950s cohort took it, so we excluded these students. We also excluded students who were already enrolled in primary schools that were selective, religious, for special needs, or for children in care, as these students were highly likely to stay in the same type of secondary school regardless of their $11+$ scores. Finally, we excluded students who did not take all five parts of the $11+$ exam. These exclusions were previously declared in the registered report. The remaining population is our base sample $(n=8087)$, comprising all Aberdeen Children of the 1950s cohort members assigned to secondary school based on the same $11+$ test score criteria (Table 1 ).

In the registered report, we stated that type of secondary school attended was known for 5112 of those in the base sample. This was incorrect. We had incorrectly included 73 people for whom secondary school is recorded as "outside Aberdeen" in the non-selective secondary school population, but for these people, there is no information about their schools' selectivity. Here we have excluded them. Figures 1 and 2 in the registered report are re-created here with the corrected study population, and exclusion of these 73 did not alter the results presented below. After this correction, there were 5039 individuals in the base sample for whom secondary school type is known. This is our study sample. Descriptive statistics comparing the total Aberdeen Children of the 1950s population base sample and the study sample are presented in Table 2.

\section{Missing data}

Lack of survey response and NHS dataset limitations mean all outcomes are not available for all participants, so we consider the results of 6 outcomes from 3 sources. Probability of responding to the 2001 survey increased with increasing $11+$ exam scores. We impute school attendance for the 3048 people in the base sample for whom secondary attendance is not known using their $11+$ exam scores, and present the effect estimates for the entire base population as a sensitivity analysis below. Probability of being linked to NHS records was higher and more stable and decreased slightly with increasing

Table 1 Exclusions from the total Aberdeen Children of the 1950s population $(n=12,148)$ for this study

In youngest school year (different exam) 2513

In private primary 216

In selective state-run primary 531

In Roman Catholic primary 260

In special needs primary 183

In special care outside Aberdeen $\quad 76$

Lack $11+$ scores 282

Total base sample $\quad 8087$

Lack secondary school attendance 3048

Total study sample 
Table 2 Descriptive statistics

\begin{tabular}{|c|c|c|c|c|c|c|c|c|c|c|}
\hline & \multicolumn{2}{|c|}{$\begin{array}{l}\text { Aberdeen Children of } \\
\text { the 1950s (total) }\end{array}$} & \multicolumn{2}{|c|}{$\begin{array}{l}\text { Base sample } \\
\text { (total) }\end{array}$} & \multicolumn{2}{|c|}{$\begin{array}{l}\text { Study sample } \\
\text { (total) }\end{array}$} & \multicolumn{2}{|c|}{$\begin{array}{l}\text { Study sample (attended } \\
\text { non-selective secondary) }\end{array}$} & \multicolumn{2}{|c|}{$\begin{array}{l}\text { Study sample (attended } \\
\text { selective secondary) }\end{array}$} \\
\hline & Cases & Mean & Cases & Mean & Cases & Mean & Cases & Mean & Cases & Mean \\
\hline Boy (\%) & 12,148 & $52 \%$ & 8087 & $52 \%$ & 5039 & $49 \%$ & 3845 & $49 \%$ & 1194 & $49 \%$ \\
\hline IQ aged 9 & 11,384 & 111 & 7998 & 110 & 4998 & 112 & 3816 & 106 & 1182 & 129 \\
\hline Father non-manual labour (\%) & 12,148 & $21 \%$ & 8087 & $17 \%$ & 5039 & $17 \%$ & 3845 & $13 \%$ & 1194 & $32 \%$ \\
\hline $11+$ exam score & 9600 & 498 & 8087 & 495 & 5039 & 502 & 3845 & 476 & 1194 & 584 \\
\hline General health (0-3 scale) & 7143 & 2.0 & 4806 & 2.0 & 4734 & 2.0 & 3542 & 1.9 & 1192 & 2.2 \\
\hline Mental health (0-15 scale) & 7111 & 8.5 & 4786 & 8.5 & 4716 & 8.5 & 3529 & 8.5 & 1187 & 8.7 \\
\hline Life limited by health (\%) & 7012 & $17 \%$ & 4720 & $17 \%$ & 4651 & $17 \%$ & 3470 & $18 \%$ & 1181 & $13 \%$ \\
\hline Linked to NHS records (\%) & 10,634 & $88 \%$ & 7181 & $89 \%$ & 4687 & $93 \%$ & 3614 & $94 \%$ & 1073 & $90 \%$ \\
\hline $\begin{array}{l}\text { Chronic diagnoses 1997-2001 } \\
\text { (per } 100 \text { people) }\end{array}$ & 10,634 & 13 & 7181 & 13 & 4687 & 11 & 3614 & 13 & 1073 & 8 \\
\hline $\begin{array}{l}\text { Chronic diagnoses 2011-2015 } \\
\text { (per } 100 \text { people) }\end{array}$ & 10,634 & 39 & 7181 & 41 & 4687 & 40 & 3614 & 44 & 1073 & 26 \\
\hline Died before age 60 (\%) & 12,148 & $8 \%$ & 8087 & $8 \%$ & 5039 & $4 \%$ & 3845 & $5 \%$ & 1194 & $3 \%$ \\
\hline Attended selective secondary (\%) & na & na & na & na & 5039 & $24 \%$ & na & na & na & na \\
\hline
\end{tabular}

test scores. Death records include those who died in the UK and abroad. Complete cases for all outcomes are shown in Table 2.

\section{Variable processing}

Details of the variables received from the Aberdeen Children of the 1950s study or from NHS hospital admissions records are given in Additional Table 1.

\section{Schools and scores}

Primary school attended is defined as the school attended in 1962 (variable RS028). Secondary school attended is available from the postal survey in 2001 (variable Q1094), with the oldest students in the cohort also having had it recorded from their education records in 1964 (variable RS095). There were no discrepancies between sources, so both were used. Selective schools were defined as the three state-run schools which required a high $11+$ exam score to attend and the three fee-paying schools which also required a high admission test score to attend. The $11+$ exam score is the sum of variables RS053-RS057, rescaled so the 540 cut-point is 0 .

\section{Self-rated health}

Overall health score is from a self-rated 4-point scale (variable Q1001), and limitations of daily activities due to health is from a self-rated presence/absence (variable Q1002). Mental health is the sum of four survey questions each on a 4-point scale, so that mental health score ranges from 0 to 15 . For both general health and mental health, a higher score is better health.

\section{Chronic disease diagnoses}

For this study, processing of hospital and mental health admission records was done by the Information Services Division (ISD) of NHS Scotland, as data protection laws require. ISD linked Aberdeen Children of the 1950s study participants via their Community Health Index number to the national hospital and mental health admission datasets SMR01 and SMR04. Each admission record includes diagnoses coded according to the International Statistical Classification of Diseases (ICD) [41]. We supplied ISD with Tonelli's set of chronic diseases and their validated ICD diagnosis codes [40] (Additional Table 1). For each individual, ISD returned a binary variable for each disease indicating presence/absence of any of the ICD codes in that disease's set within the given 5year window (1997-2001 or 2011-2015). We summed the number of chronic diseases diagnosed during each window to one variable. ISD also provided a variable indicating if the participant had no Community Health Index number and therefore could not be linked to medical records.

\section{Death}

Death records are available for all participants in the UK and those who were reported from abroad for all years since study inception. Age of death was derived from the date of death and the age in months in December 1962.

\section{Covariates}

Father's occupation at child's birth has previously been classified using The Registrar General's Classification of Occupations 1950 [38]. Father's occupation (variable RS040) was considered a non-manual labour if his 
occupation was coded class I or II. IQ at age 9 was given by variable RS052.

\section{Hypotheses}

The pre-registered hypotheses were as follows:

(H0) Selective secondary school attendance is not associated with self-reported overall health in mid-life. (H1) Selective secondary school attendance is not associated with self-reported mental health in mid-life. (H2) Selective secondary school attendance is not associated with limiting health problems in mid-life.

(H3) Selective secondary school attendance is not associated with chronic disease diagnoses in mid-life.

(H4) Selective secondary school attendance is not associated with chronic disease diagnoses in later life.

(H5) Selective secondary school attendance is not associated with risk of death by age 60 .

\section{Primary model}

As registered, our primary modelling strategy modelled the schooling-health effect using a non-parametric, linear approximation local to the score cut-point. This method considers a bandwidth of scores around the cut-point and fits a regression function for each population on either side of the cut-point, giving more weight to observations closer to the cut-point. Bandwidth was chosen automatically using the mean square error optimal method [42] and a triangular kernel function used to assign weights to the observations within the bandwidth. The difference in outcome due to selective schooling is then the difference of the intercepts at the cut-point.

To account for the fuzziness of the score-assignment relationship, we estimated the effect of selective schooling as the ratio of the effect given the probability of attendance (equivalent to local average treatment effect estimation in randomised controlled trials) $[35,36]$. To do so, we used a two-stage least squares method, where the first stage was a model of the probability of attending a selective school contingent on exam score, the cut-points and their interaction. This probability of treatment was then used instead of a binary treatment variable in the second stage.

\section{Sensitivity analyses}

The registered secondary analyses for each outcome were to report effect estimates for (1) variation in bandwidth selection, (2) higher-order polynomial form, (3) inclusion of covariates (sex, IQ score at age 9, father's occupation), (4) exclusion of the population immediately around the cut-off, and (5) inclusion of those for whom secondary school attended is not known (imputed by inverse-probability weighting using the $11+$ score).

\section{Power}

As detailed in the registered report, analysis of statistical power for regression discontinuity designs suggests that to detect a small difference ( 0.2 of a standard deviation) between two means at the $2.5 \%$ level (one-tailed) with $95 \%$ power would require a sample size of 1753 , with $80 \%$ power for a sample size of 1078 . For a large effect size ( 0.8 of a standard deviation), the sample sizes were 109 and 68 respectively. These results suggest that regression discontinuity designs' sample size is around 2.7 times higher than the corresponding RCT [43].

Average self-rated health in the Aberdeen Children of the 1950s study was 2 with a standard deviation of 0.8 . For a small effect ( 0.2 of a standard deviation) at the $5 \%$ level with $80 \%$ power and taking account of the relative size of the exposure groups, the regression discontinuity sample size applying the correction is 2762 , and for a large effect ( 0.8 of a standard deviation), it is 201 .

Given the assumptions that underlie these estimates, for this design it is prudent to assess the results in totality rather than focussing on the achievement of statistical significance at a given level on any one test. We assess whether effect sizes were consistent across outcomes and robust across sensitivity analyses, whether the magnitude of the effect sizes is plausible, and whether the conclusions are in line with other studies.

\section{Software}

Two-stage least squares was done in $\mathrm{R}$ using the package AER [44] and bandwidth optimisation and McCrary tests done with the package rddapp [45]. The metadata and all code used for analysis and generation of figures and tables are included (Additional file 2).

\section{Results \\ Validity of the design}

The study design assumes that in the absence of an effect of selective schooling, there would be a smooth relationship between the 11+ exam score and health. In contrast, the presence of an effect of selective schooling would be seen as a discontinuity at the score cut-pointthere would be a change in the mean level of health between people who scored just to either side of the cutpoint.

To determine if the study represents a natural experiment that can be analysed for a regression discontinuity, we conducted several tests of validity. These tests are all based around the idea that aside from school assignment, there should be no other discontinuities of study population characteristics across the cut-point, including in the covariates or in attrition over time.

The distribution of the 11+ assignment scores in the study sample was smooth across both cut-points 
(McCrary density function test of discontinuity [46] at score of $0, p=0.76$ at score $=20, p=0.50$ ) indicating no manipulation of the scores to influence school assignment for children close to the cut-point (Fig. 1).

For a valid design, confounders (sex, IQ at age 9, father's occupation at birth) should also be smooth across the assignment cut-point. Discontinuities in these variables would call into question the validity of the test score as a forcing variable for school attendance [36]. IQ at age 9 , probability of being a boy, and probability of father's occupation being non-manual are all smooth across the range of $11+$ exam scores (Additional Figure 1). In addition, measuring the discontinuity of these confounders at the cut-point using the primary model did not find evidence for any difference (Table 3 and Additional Figure 1). Altering the bandwidth used in the model did not change these results although the smallest bandwidth estimates are non-zero but very imprecise (Additional Figure 1).

Similarly, probability of replying to the 2001 postal survey or being linked to NHS records (the sources of the outcome data) should be smooth across the assignment cut-point. Likelihood of replying to the survey increased for increasing 11+ score but was smooth across the cut-point [33]. Probability of being linked to NHS records decreased slightly with increasing $11+$ score but selective secondary school attendance did not affect it (Table 3). We analysed potential confounding and attrition bias by controlling outcome models for confounding and by weighting using inverse-probability weighting for the likelihood of replying to the survey (results below).

The $11+$ score was a strong but not perfect predictor of selective school assignment (Fig. 2). In the registered report, we declared we would use a single cut-point when modelling this first stage, but this gave fairly poor estimates of probability of attending secondary school because the slope of relationship between $11+$ score and secondary school attendance changed at both points. For the analysis here, we use both cut-points to estimate the first stage probability of attending a selective school (Fig. 2). The second stage estimates remain local treatment effects for an $11+$ score at the primary cut-point of 0 .

\section{Effect of selective schooling on self-reported health in mid-life}

Study members reported on three measures of their health by survey when they were in their late 40 s to early 50s-their general health, their mental health, and whether they had an illness that limited their lives.

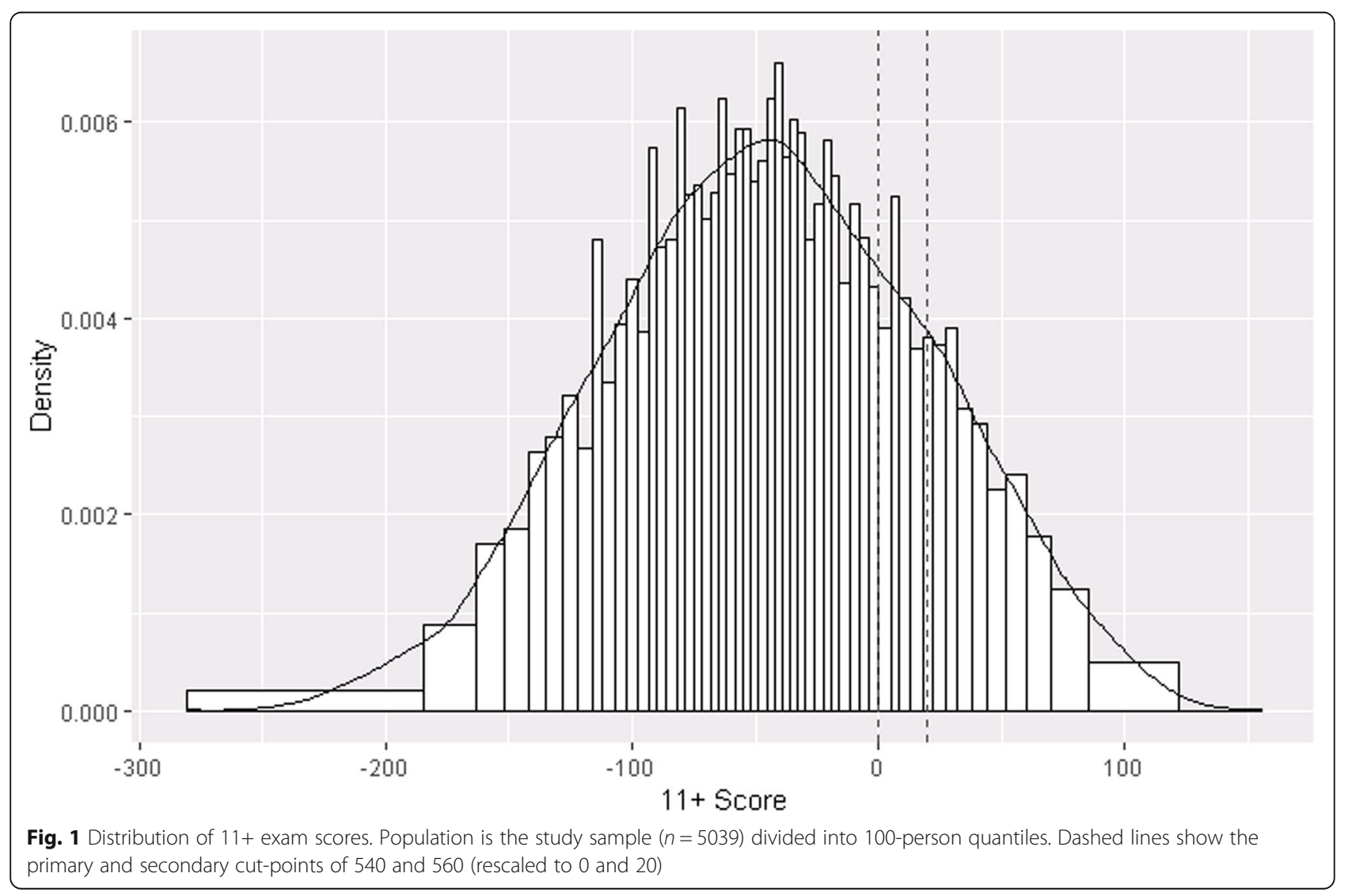


Table 3 Estimated effect of attending a selective secondary school on confounding variables

\begin{tabular}{|c|c|c|c|c|c|}
\hline & Effect size & $95 \% \mathrm{Cl}$ & $p$ value & $n$ & Bandwidth \\
\hline IQ age 9 & -0.14 & $(-1.49$ to 1.21$)$ & 0.84 & 3441 & 77 \\
\hline Boy & -0.01 & $(-0.08$ to 0.06$)$ & 0.82 & 4330 & 111 \\
\hline Father non-manual occupation & 0.02 & $(-0.05$ to 0.09$)$ & 0.63 & 3570 & 79 \\
\hline Linked to NHS records & 0.00 & $(-0.03$ to 0.03$)$ & 0.93 & 4892 & 163 \\
\hline
\end{tabular}

For all three outcomes, health was better as $11+$ scores increased (Fig. 3a, d, and g) and those who attended selective school had better mean scores (Table 2).

However, isolating the effect of selective schooling itself (modelled as linear within the predicted optimal bandwidth and weighting the responses of those closer to the cut-off more highly) showed that people who attended selective schools reported slightly poorer general health than we would expect given their test score (Fig. 3b). The effect of selective schooling was -0.12 on the 4-point scale of general health (0.15 of a standard deviation poorer) (Table 4).

The effect of selective schooling on mental health and life limitation were also negative; however, these estimates were imprecise with confidence interval including positive effects as well (Table 4 and Fig. 3e, h). The effect estimate for mental health was -0.2 on the 16-point scale $(0.10$ of a standard deviation poorer). The estimate for probability of having a life limitation was 5 percentage points higher ( 0.14 of a standard deviation more likely).

\section{Effect of selective schooling on chronic disease burden in mid-life}

We also assessed health at mid-life using hospital admission records. We calculated the number of unique chronic diseases diagnosed in all hospital admissions during the 5 years before participants reported their health values given above.

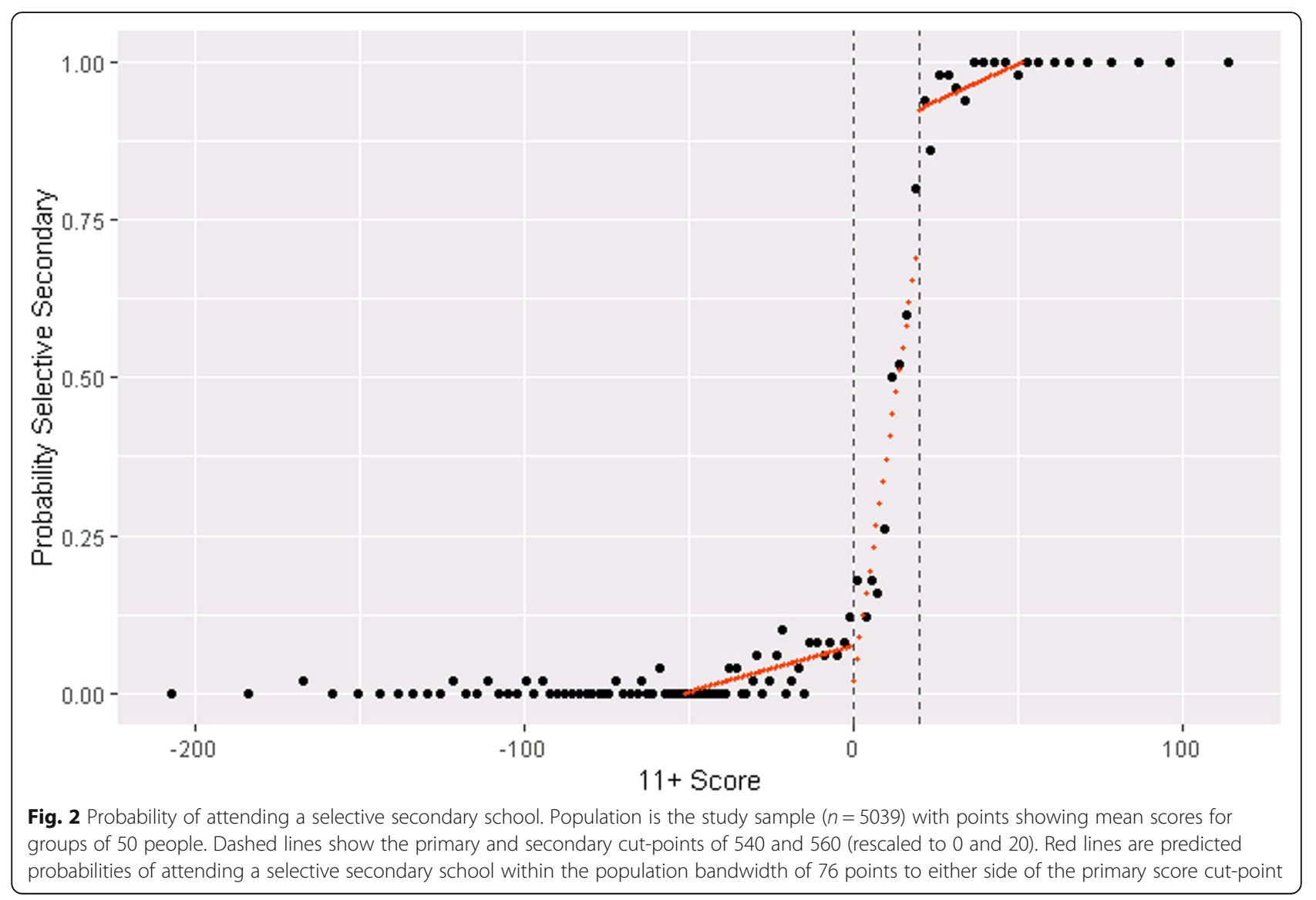




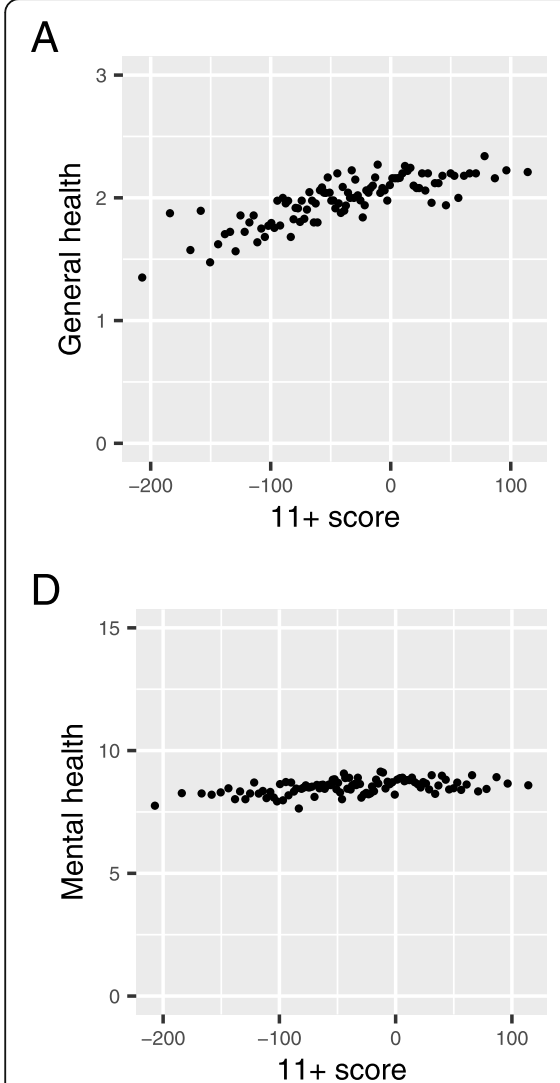

G

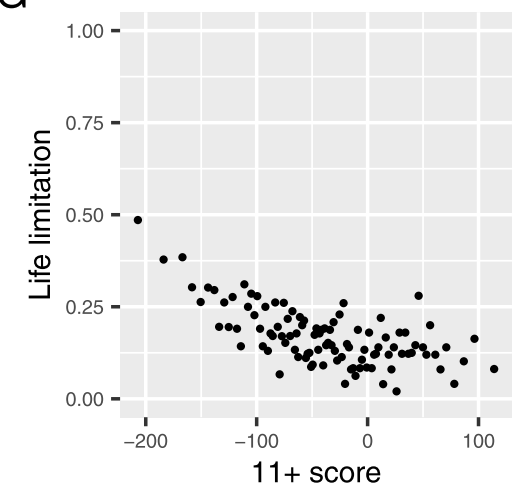

B

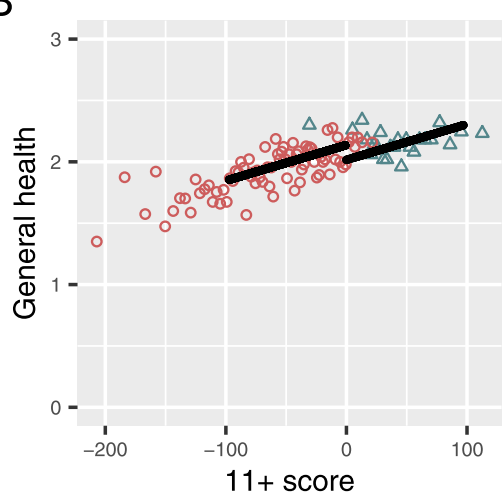

E

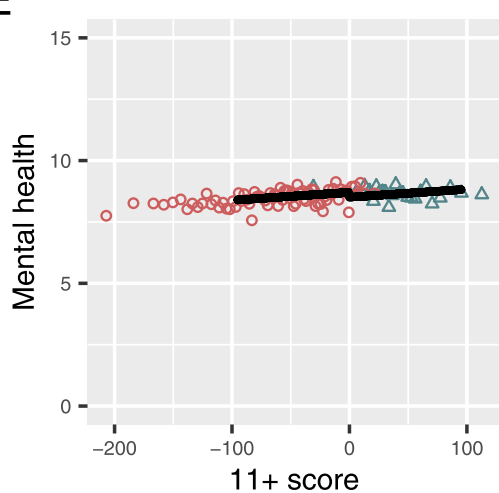

$\mathrm{H}$

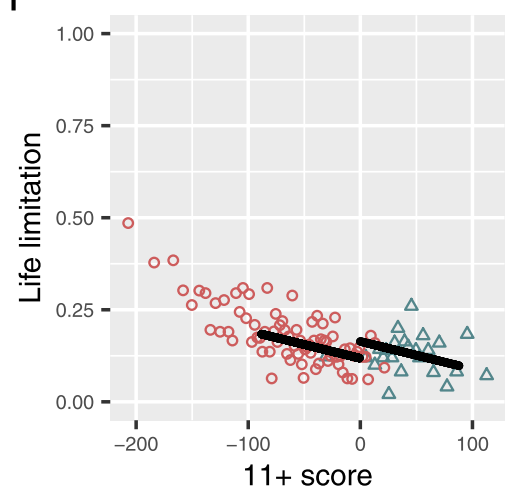

C

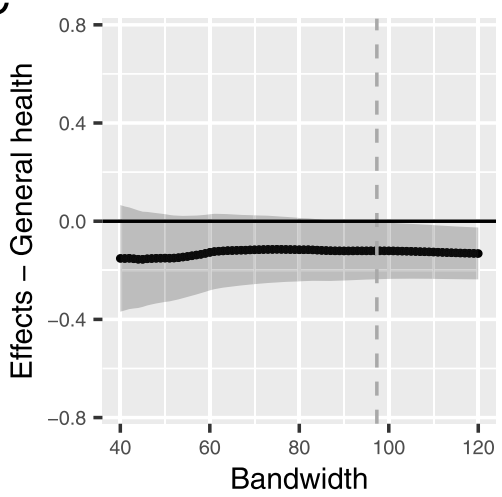

$\mathrm{F}$

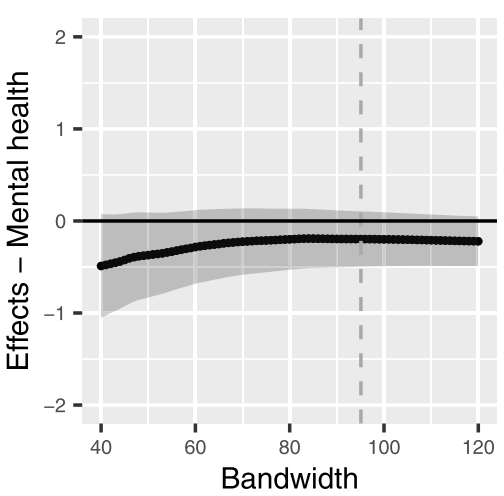

I

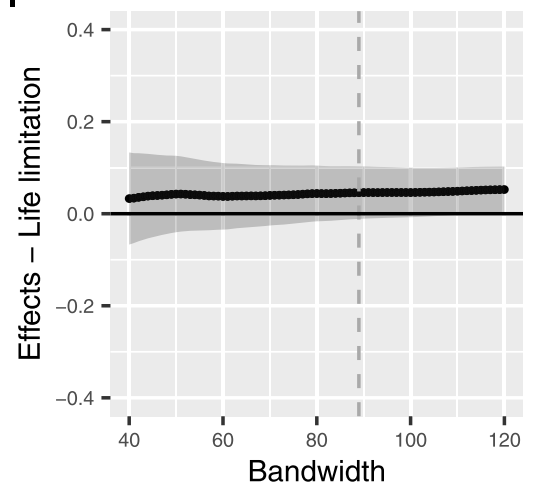

Fig. 3 Assessment of the effect of selective schooling on the self-reported health outcomes. Population is the study sample ( $n=5039$ ) and points are means of 50 people. $\mathbf{a}, \mathbf{d}, \mathbf{g}$ The first column shows the 11+ exam score vs the outcome. $\mathbf{b}$, e, $\mathbf{h}$ The second column shows the same data with the population separated by selective (open orange triangles) and non-selective (open blue circles) secondary school attendance. The line shows the estimated effect size of secondary school attendance at the cut-point extrapolated across the optimal bandwidth. $\mathbf{c}$, $\mathbf{f}$, $\mathbf{i}$ The third column shows re-estimates of the effect size of secondary school attendance for a range of population sizes around the cut-point (bandwidth sizes). The effect size estimate at the predicted optimal bandwidth (reported in Table 4) is shown as a dashed line

As with the self-reported health outcomes, chronic disease burden in mid-life was better (lower) with increasing 11+ scores (Fig. 4a) and those who attended selective schools had a lower mean number of diagnoses (Table 2). The estimated effect of selective schooling itself on the number of chronic disease diagnoses at mid-life was 3 fewer diagnoses per 100 people $(0.07$ of a standard deviation) but imprecise with confidence interval including more diagnoses as well (95\% CI 9 fewer to 4 more per 100 people) (Table 4 and Fig. 4b).

\section{Effect of selective schooling on chronic disease burden in later life and on premature death}

To evaluate health in later life, we also calculated the number of unique chronic diseases diagnosed across all 
Table 4 Estimated effect of attending a selective secondary school on health outcomes

\begin{tabular}{llllll}
\hline & Effect size & $95 \% \mathrm{Cl}$ & $p$ value & $n$ & bandwidth \\
\hline General health (0-3 scale) & -0.12 & $(-0.24$ to 0.00) & 0.04 & 3891 & 97 \\
Mental health (0-15 scale) & -0.20 & $(-0.50$ to 0.10$)$ & 0.20 & 3824 & 95 \\
Life limited by health & 0.05 & $(-0.01$ to 0.10$)$ & 0.12 & 3632 & 89 \\
Chronic disease diagnoses per person 1997-2001 & -0.03 & $(-0.09$ to 0.04) & 0.46 & 3238 & 78 \\
Chronic disease diagnoses per person 2011-2015 & 0.09 & $(-0.03$ to 0.20) & 0.13 & 4138 & 119 \\
Died before age 60 & 0.00 & $(-0.02$ to 0.03$)$ & 0.74 & 4821 & 151 \\
\hline
\end{tabular}

hospital admissions from 2011 to 2015 when the participants were in their early to mid-60s.

The chronic disease burden had more than tripled across the population (Table 2), and the number of diagnoses decreased steeply with increasing $11+$ scores compared to mid-life (Fig. 4d). The mean burden remained lower in those who attended selective schooling (Table 2).

However, the effect of selective schooling itself on number of chronic disease diagnoses in later life was estimated to be an additional 9 diagnoses per 100 people ( 0.10 of a standard deviation), though the estimate was imprecise with confidence interval including fewer diagnoses as well (95\% CI between 3 fewer and 20 more diagnoses per 100 people) (Fig. 4e and Table 4).

We also evaluated the likelihood of dying before age 60. Overall, there was a low chance of premature death (4\%) that decreased with increasing $11+$ score, with the mean likelihood halved in those attending selective schooling (Fig. 4g and Table 2).

The estimated effect of selective secondary school attendance on premature death was no difference though the estimate was imprecise (95\% CI from 2 percentage points lower to 3 percentage points higher) (Table 4 and Fig. 4h).

\section{Effect of selective schooling on completing a higher degree}

To test our primary model against a known positive control, we evaluated the effect of selective schooling on the likelihood of attaining a higher degree. At the cut-point, attending a selective secondary school increased the probability of attaining a higher degree by 16 percentage points ( $95 \%$ CI 10 to 22 percentage points).

\section{Sensitivity analyses}

Five parameters were varied to test the robustness of the estimated effects of secondary schooling. These were as follows: (1) the population size used to make the model, (2) the weight given to individuals nearer the cut-point, (3) the use of second or third order polynomials of the $11+$ score in the model, (4) the inclusion of confounders (sex, IQ at age 9 and father's occupation at birth), and (5) the inclusion by imputation of the population whose secondary school attendance was not known.

For each of the outcomes presented above, the population around the cut-point used to construct the model (referred to as the bandwidth) was chosen automatically using the mean square error optimal method that balances potential bias from wider bandwidth against increased variance of a smaller bandwidth [42].

To test the robustness of the predicted effect estimates to using different population sizes to create the model, we varied the bandwidth from 40 to 120 points to either side of the score cut-point, giving population sizes from 1980 to 4489 . The minimum of 40 was used to ensure inclusion of data points after the second score cut-point of 20 . Besides varying the bandwidth, all other parameters were identical to those in the primary model results shown above.

The third columns in Figs. 3 and 4 show the predicted effect sizes of attending a selective schooling for the range of populations to either side of the cut-point (81 effect size predictions are shown per outcome). The predicted effects are consistent across the range and gain precision as the population size increases. These results support a small negative effect of selective secondary schooling on self-reported outcomes across the range of bandwidths (Fig. 3c, f, i), but there is no clear evidence for an effect on hospital or mortality outcomes (Fig. 4c, $\mathrm{f}$, i). For all outcomes (except the largest bandwidths for general health in mid-life), the confidence intervals of the estimates cross zero effect.

Figures 5 and 6 show the estimated effect of attending selective secondary school on the health outcomes: (1) using higher weights for those closer to the cut-point (triangular); (2) using equal weights; (3) including confounders of sex, IQ at age 9, and father's occupation; (4) including the 3048 people in the base sample for whom secondary school was not known using inverse-probability weighting; (5) excluding those whose probability of attending selective secondary was not 0 or $100 \%$ (donut analysis); and (6) including the entire population equally weighted. Each 

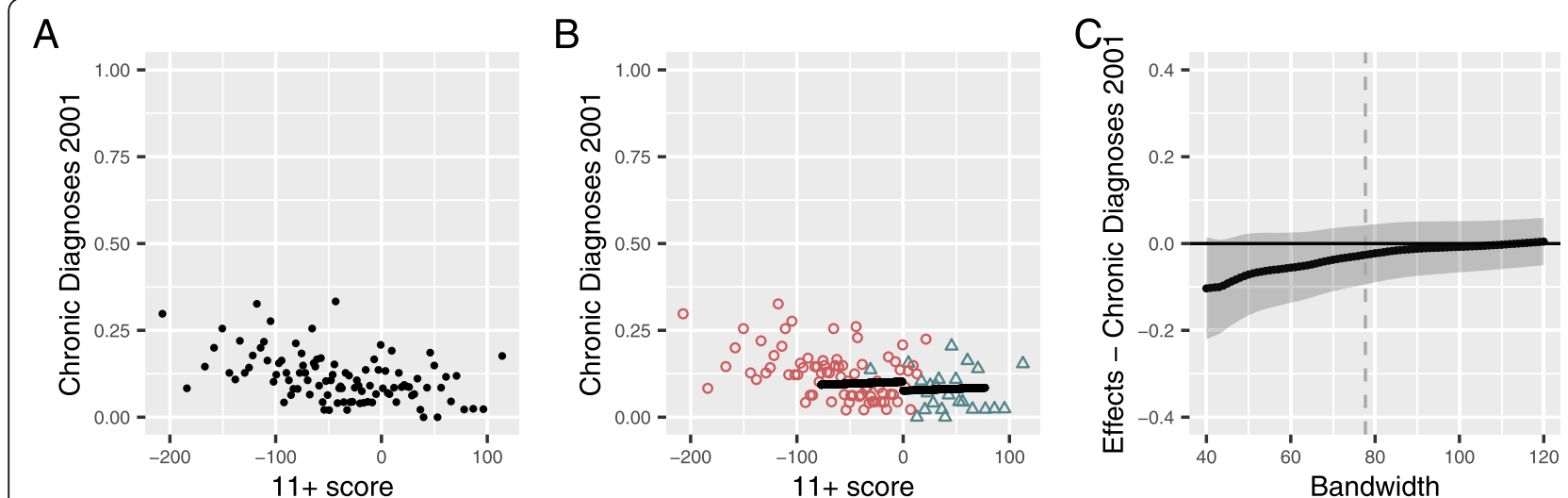

$\mathrm{D}$

$\mathrm{E}$
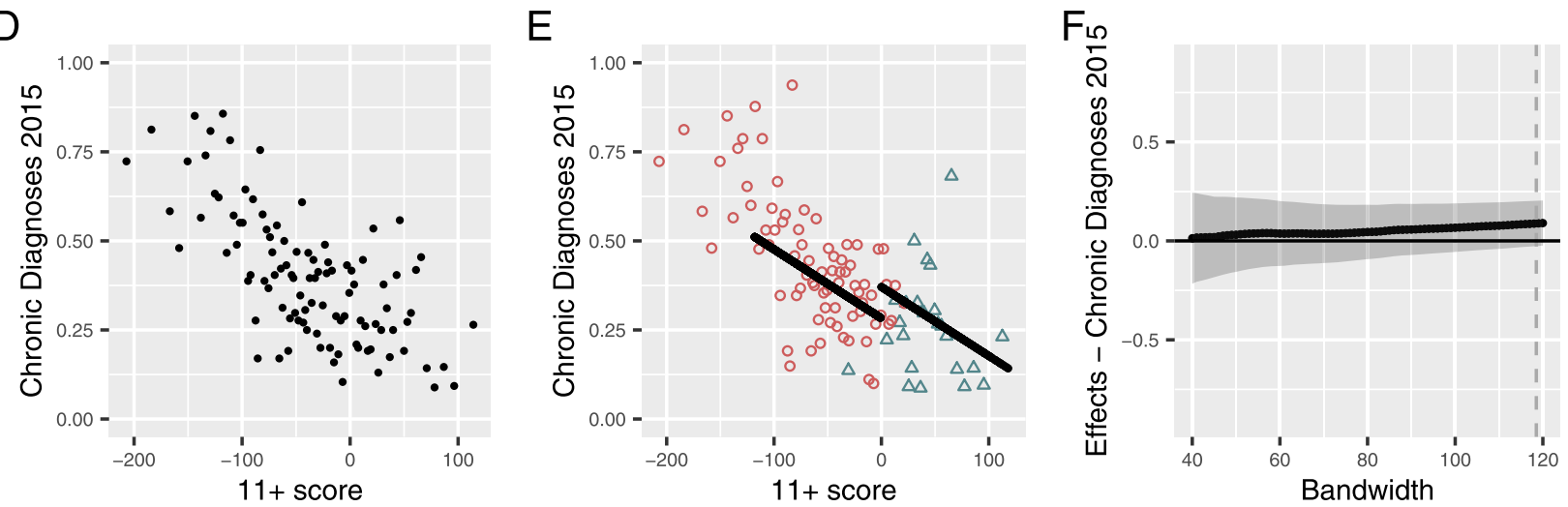

G

$\mathrm{H}$
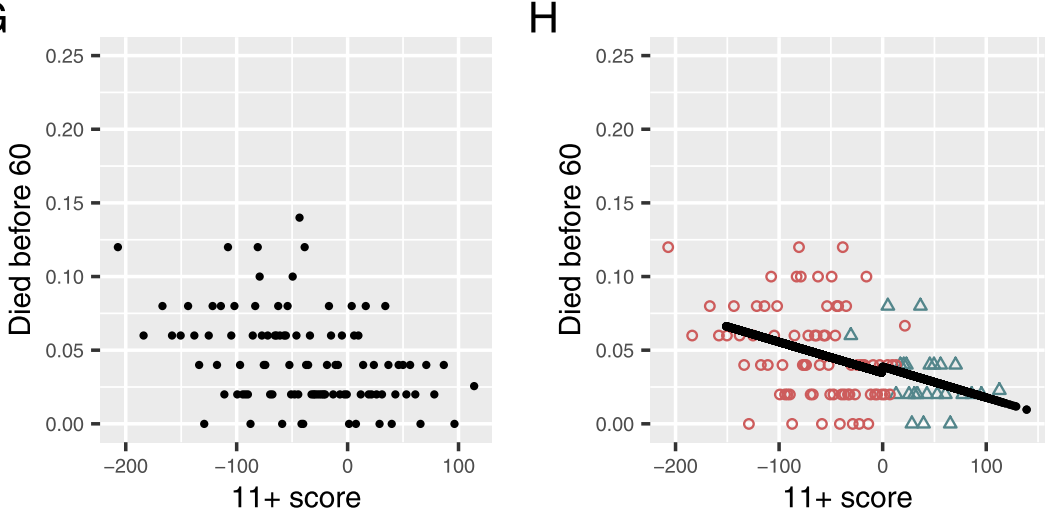

I

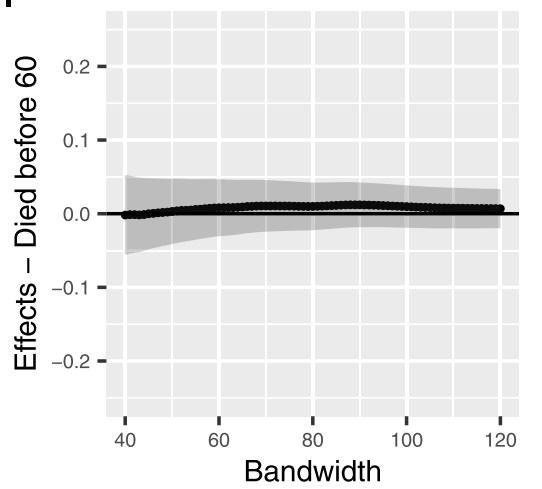

Fig. 4 Assessment of the effect of selective schooling on outcomes derived from hospital and death records. Population is the study sample $(n=$ 5039) and points are means of 50 people. $\mathbf{a}, \mathbf{d}, \mathbf{g}$ The first column shows the $11+$ exam score vs the outcome. $\mathbf{b}, \mathbf{e}, \mathbf{h}$ The second column shows the same data with the population separated by selective (open orange triangles) and non-selective (open blue circles) secondary school

attendance. The line shows the estimated effect size of secondary school attendance at the cut-point extrapolated across the optimal bandwidth. $\mathbf{c}, \mathbf{f}, \mathbf{i}$ The third column shows re-estimates of the effect size of secondary school attendance for a range of population sizes around the cut-point (bandwidth sizes). The effect size estimate at the predicted optimal bandwidth (reported in Table 4) is shown as a dashed line

of these variations was evaluated for first-, second-, or third-order polynomials of the $11+$ exam score. Effect sizes, confidence intervals and $p$ values for these estimates are given in Additional Table 2.

These sensitivity analyses consistently produced estimates of a small (but imprecise) negative effect of selective schooling on the self-reported health outcomes; no effect on the likelihood of dying prematurely or on chronic disease diagnoses at mid-life and negative but imprecise estimates for chronic disease diagnoses in later life-all consistent with the primary model.

\section{Discussion}

We found that people who attended selective secondary school had better health. This was true of health measures that were self-reported or derived from 


\section{General Health}

Triangle weights - linear

Triangle weights - squared

Triangle weights - cubed

Equal weights - linear

Equal weights - squared

Equal weights - cubed

Including confounders - linear Including confounders - squared

Including confounders - cubed

Missing school imputed - linear

Missing school imputed - squared

Missing school imputed - cubed

Excluding scores from -20 to 60

Including all scores

Triangle weights - linear

Triangle weights - squared

Triangle weights - cubed

Equal weights - linear

Equal weights - squared

Equal weights - cubed

Including confounders - linear

Including confounders - squared

Including confounders - cubed

Missing school imputed - linear

Missing school imputed - squared

Missing school imputed - cubed

Excluding scores from -20 to 60

Including all scores

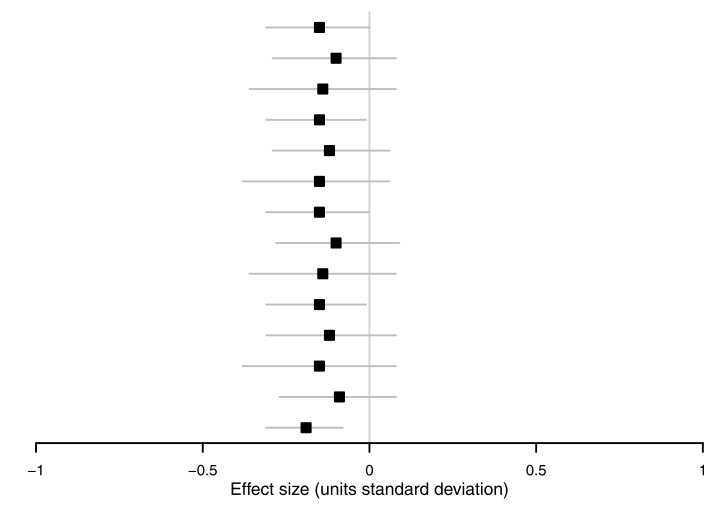

Mental Health

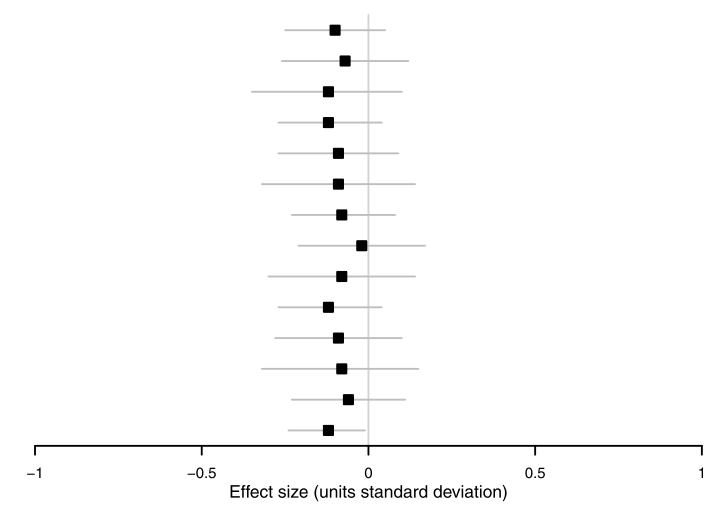

\section{Life limitation}

Triangle weights - linear

Triangle weights - squared

Triangle weights - cubed

Equal weights - linear

Equal weights - squared

Equal weights - cubed

Including confounders - linear

Including confounders - squared

Including confounders - cubed

Missing school imputed - linear

Missing school imputed - squared

Missing school imputed - cubed

Excluding scores from -20 to 60

Including all scores

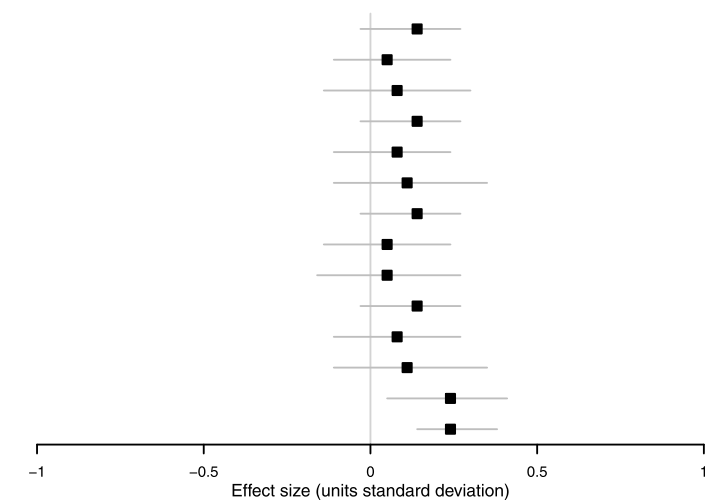

Fig. 5 Sensitivity analysis of the estimated effect of selective schooling on the health outcomes self-reported at mid-life. Analyses are (1) using higher weights for those closer to the cut-point (triangular); (2) using equal weights; (3) including confounders of sex, IQ at age 9, and father's occupation; (4) including the 3048 people in the base sample for whom secondary school was not known using inverse-probability weighting; (5) excluding those whose probability of attending selective secondary was not 0 or $100 \%$ (donut analysis); and (6) including the entire population equally weighted. Each of these variations was evaluated for first-, second-, or third-order polynomials of the $11+$ exam score. Each sensitivity analysis effect estimate is represented as a point with associated $95 \%$ confidence intervals

government records, whether measured in mid-life or later life. Importantly, we also found that in addition to better health, people who attended selective secondary school had more advantaged socioeconomic backgrounds, higher childhood IQs, and higher likelihood of getting a university degree.

However, we did not find evidence that selective schooling itself improved health. We measured selective schooling's 


\section{Chronic disease diagnoses mid-life}
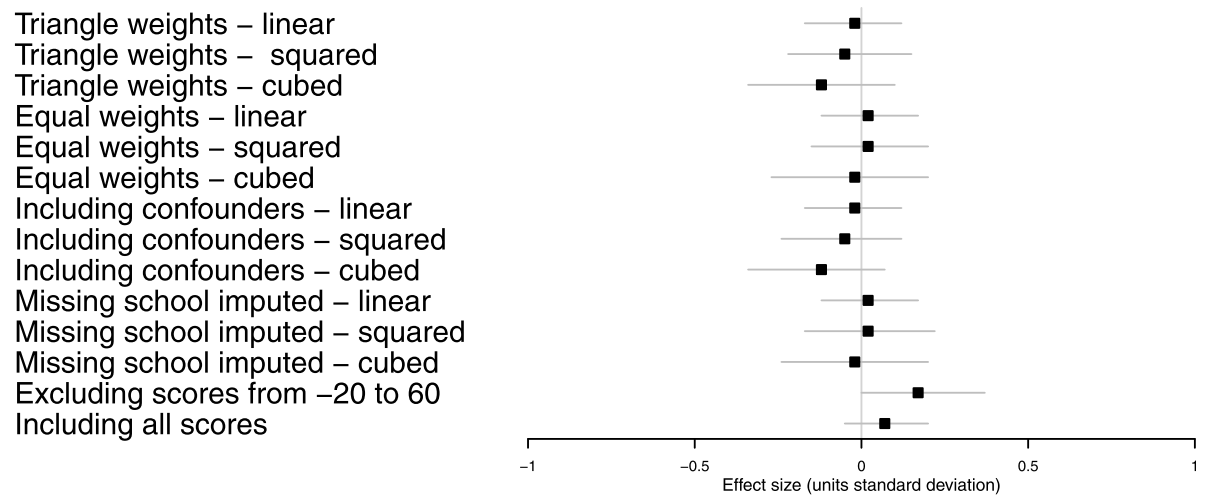

\section{Chronic disease diagnoses late-life}

Triangle weights - linear Triangle weights - squared Triangle weights - cubed Equal weights - linear Equal weights - squared Equal weights - cubed Including confounders - linear Including confounders - squared Including confounders - cubed Missing school imputed - linear Missing school imputed - squared Missing school imputed - cubed Excluding scores from -20 to 60 Including all scores

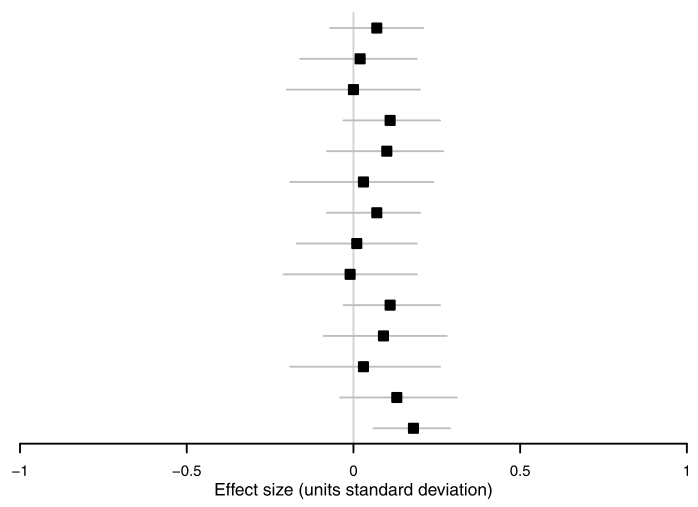

\section{Died before 60}

Triangle weights - linear Triangle weights - squared Triangle weights - cubed Equal weights - linear Equal weights - squared Equal weights - cubed Including confounders - linear Including confounders - squared Including confounders - cubed Missing school imputed - linear Missing school imputed - squared Missing school imputed - cubed Excluding scores from -20 to 60 Including all scores

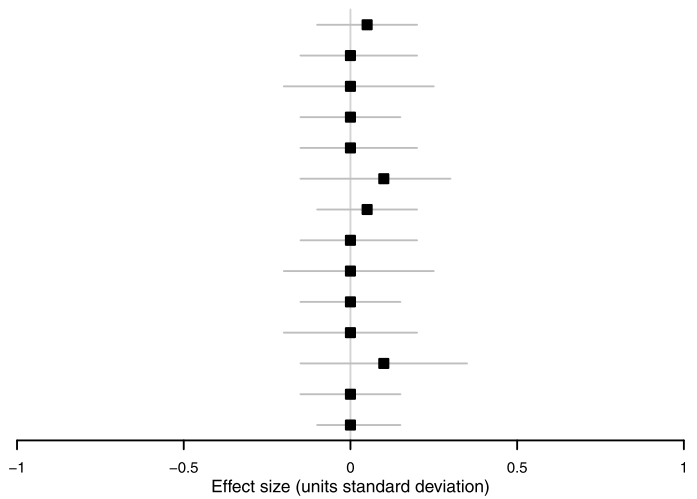

Fig. 6 Sensitivity analysis of the estimated effect of selective schooling on the health outcomes from hospital admission and death records. Analyses are (1) using higher weights for those closer to the cut-point (triangular); (2) using equal weights; (3) including confounders of sex, IQ at age 9, and father's occupation; (4) including the 3048 people in the base sample for whom secondary school was not known using inverseprobability weighting; (5) excluding those whose probability of attending selective secondary was not 0 or 100\% (donut analysis); and (6) including the entire population equally weighted. Each of these variations was evaluated for first-, second-, or third-order polynomials of the $11+$ exam score. Each sensitivity analysis effect estimate is represented as a point with associated $95 \%$ confidence intervals

effect on self-reported health in mid-life, chronic disease burden in mid-life and late-life derived from hospital records, and the likelihood of dying prematurely. Estimates of selective schooling's effect on these measures were primarily none or negative. This lack of a positive influence of selective secondary schooling on health was consistent despite varying a wide range of the model's assumptions. The effect sizes ranged from 0.10 to 0.15 standard deviations worse for self-reported health, and from 0.02 standard deviations better to 0.07 worse for record-derived health. None of 
these results reach the 0.25 standard deviation difference marking the threshold of an educational intervention of substantive importance [47]. Furthermore, the estimates were too imprecise to allow us to conclude selective schooling was detrimental without further study.

We were able to isolate the effect of selective schooling by using a natural experiment in secondary school assignment in the UK. The Aberdeen Children of the 1950s study began during the era of school assignment by test score and collected data on an entire large population, removing the bias that can occur in voluntary enrolment studies. The population was assigned to school using the same test and criteria, removing measurement error present when considering school assignment in countrywide studies where test and threshold scores often vary. Because the study has run for the past 50 years, we were able to assess the effect of schooling on health long term, and Scotland's data sharing policies mean we were able to link to routinely collected data rather than rely solely on self-reports, removing participation bias and increasing the range of health outcome measures. We found no evidence that associations between confounders and cognitive ability changed at the assignment point, suggesting risk of confounding bias is low in the design. There was also no evidence that cognitive ability's association with questionnaire response or being traced in the NHS changed at the assignment point, suggesting risk of participation bias is also low. Furthermore, sensitivity analyses controlling for confounders and weighted for nonresponse to the survey showed little impact on the results. This evidence together suggests the natural experiment was well-identified and the design well-controlled for confounding.

In evaluating these results within the body of work on education and health, we see that previous research (including in this cohort) has shown that attending selective secondary school increases length of time in school [23]. However, there is mixed evidence that this has a causal effect on health. One natural experiment study exploiting the legislated rising of the school leaving age in Britain in 1972 suggests it led to reduced mortality risk and better health outcomes in UK Biobank participants [13]. In contrast, and in line with this work, a study using the same natural experiment and a similar one in 1947 found little effect on mortality across England and Wales [11].

If higher income is a mechanism by which health advantage is gained, this pathway may not have existed in our population. Previous research did not find an effect of selective schooling on income in this cohort [23], possibly due to the economic boom related to North Sea oil production as they entered employment, when qualifications were less important for labour market success. However, a recent study using the 1958 English birth cohort uses a proxy of the $11+$ score in a regression discontinuity design and found an effect of selective secondary schooling on educational attainment, but no effect on income or health, in line with our findings [48].

Despite the strong natural experiment design, our results may still be biased. The study was designed to calculate the effects specific to people with an $11+$ score at the assignment cut-point, so any heterogeneous impacts of selective schooling will be missed. Furthermore, despite having a large sample, the design favours reduction of confounding bias over precision, and small effects may have been missed. We sought to mitigate these limitations by looking at multiple health outcomes and using comprehensive sensitivity analyses, which showed consistent direction of effect.

\section{Conclusions}

We did not find evidence that selective schooling had a positive effect on self-reported or record-derived health in mid-life or later life in a large Scottish population. The rationale given for expanding selective secondary schooling in the UK is centred on educational advantages, but findings from this and similar work suggest that the advantages should not be extended to include health benefits. As population well-being is often judged by economic and health success, these findings suggest that the separating school-children by ability is not an efficient way to make changes.

\section{Supplementary information}

Supplementary information accompanies this paper at (https://doi.org/10. 1186/s12916-020-01536-7).

Additional file 1: Table S1. Study variables. (Excel spreadsheet) giving the source, description, time frame, and possible values of all the variables received from the Aberdeen Children of the 1950s study or from NHS hospital admissions records.

Additional file 2: Study code. (Plain text file) giving the metadata and all code used for analysis and generation of figures and tables in this paper.

Additional file 3: Figure S1. Assessment of the smoothness of the confounding variables across the selective schooling cut-point. Population is the study sample $(n=5039)$ and points are means of 50 people. Figures $A, D$ and $G$ in first column show the $11+$ exam score vs the confounder. Figures $B, E$ and $H$ in the second column show the same data with the population separated by selective (open orange triangles) and non-selective (open blue circles) secondary school attendance. The line shows the estimated effect size of secondary school attendance at the cut-point extrapolated across the optimal bandwidth. Figures C, F and I in the third column show re-estimates of the effect size of secondary school attendance for a range of population sizes around the cut-point (bandwidth sizes). The effect size estimate at the predicted optimal bandwidth (reported in Table 3) is shown as a dashed line.

Additional file 4: Table S2. Effect size estimates from sensitivity analyses. (Excel spreadsheet) giving estimated effect of attending selective secondary school on the health outcomes: 1) using higher weights for those closer to the cut-point (triangular); 2) using equal 
weights; 3) including confounders of sex, $1 \mathrm{Q}$ at age 9 and father's occupation; 4) including the 3048 people in the base sample for whom secondary school was not known using inverse-probability weighting; 5) excluding those whose probability of attending selective secondary was not 0 or $100 \%$ (donut analysis); and 6) including the entire population equally weighted. Includes evaluation for first, second, or third order polynomials of the 11+ exam score. Also includes effect sizes, confidence intervals, and $p$-values calculated in units of standard deviation of the the study sample.

\section{Acknowledgements}

This study would not have been possible without the assistance of Heather Clark and the team managing the Aberdeen Children of the 1950s study, the research coordinators and analysts at the Grampian Data Safe Haven, and the teams at the Administrative Data Research Centre - Scotland and the electronic Data Research and Innovation Service (eDRIS) at NHS Scotland.

\section{Funding}

This project is funded by the Economic and Social Research Council grant number ES/L007487/1 (Administrative Data Research Centre - Scotland). FP, $\mathrm{RD}, \mathrm{PC}$, and $\mathrm{MHB}$ are also funded by the Medical Research Council [MC_UU_12017/13, MC_UU_12017/15] and the Scottish Government Chief Scientist Office [SPHSU13, SPHSU15].

\section{Availability of data and materials}

The anonymised datasets generated and analysed during the current study are available in the Scottish National Data Safe Haven repository under the project identifier 1718-0208. As the study uses sensitive education and patient data, access is restricted by law to approved researchers for use within National Data Safe Havens only (the authors do not hold a copy of the datasets). Access is governed by the electronic Data Research and Innovation Service of the Information Services Division of NHS Scotland, with details available here https://www.isdscotland.org/Products-and-Services/ EDRIS/.

The code used to generate and analyse the data in the current study are included here as Supplementary file 1.

\section{Authors' contributions}

FP had the initial idea for the study. JB and FP designed the study and analysed the data with inputs from all authors. JB and FP drafted the paper and all authors contributed to the data interpretation and critical revision of the manuscript. All authors read and approved the final manuscript.

\section{Ethics approval and consent to participate}

Approvals for this research were received from the Aberdeen Children of the 1950s study steering committee (project identifier ACONF046), the NHS Scotland Public Benefit and Privacy Panel for Health and Social Care Research (project identifier 1718-0208), and the Administrative Data Research Network research approvals panel (project identifier PROJ-143).

\section{Consent for publication}

Not applicable.

\section{Competing interests}

The authors declare that they have no competing interests.

\section{Author details}

${ }^{1}$ Centre for Health Data Science, University of Aberdeen, Aberdeen AB25 2ZD, UK. ${ }^{2} \mathrm{MRC} / \mathrm{CSO}$ Social and Public Health Sciences Unit, University of Glasgow, 200 Renfield Street, Glasgow G2 3AX, UK. ${ }^{3}$ Institute of Geography, University of Edinburgh, Drummond Street, Edinburgh EH8 9XP, UK.

\section{Received: 2 October 2018 Accepted: 18 February 2020} Published online: 03 April 2020

\section{References}

1. UNESCO, Education for All, editor. Education for All by 2015: will we make it? Paris: UNESCO; 2007.

2. WHO Commission on Social Determinants of Health, World Health Organization, editor. Closing the gap in a generation: health equity through action on the social determinants of health: Commission on Social Determinants of Health final report. Geneva: World Health Organization, Commission on Social Determinants of Health; 2008.

3. Feinstein $L$, Sabates $R$, Anderson $T$, Sorhaindo A, Hammond C. What are the effects of education on health? In: Measuring the Effects of Education on Health and Civic Engagement. Paris: OECD Publishing; 2006.

4. Montez JK, Friedman EM. Educational attainment and adult health: under what conditions is the association causal? Soc Sci Med. 2015;127:1-7.

5. Baker DP, Leon J, Smith Greenaway EG, Collins J, Movit M. The education effect on population health: a reassessment. Popul Dev Rev. 2011;37:307-32.

6. Mirowsky J, Ross CE. Education, social status, and health. New York: A. de Gruyter; 2003.

7. Smith WC, Anderson E, Salinas D, Horvatek R, Baker DP. A meta-analysis of education effects on chronic disease: the causal dynamics of the population education transition curve. Soc Sci Med. 2015;127:29-40.

8. Ljungdahl S, Bremberg SG. Might extended education decrease inequalities in health? — a meta-analysis. Eur J Pub Health. 2015:25:587-92.

9. Hamad R, Elser H, Tran DC, Rehkopf DH, Goodman SN. How and why studies disagree about the effects of education on health: a systematic review and meta-analysis of studies of compulsory schooling laws. Soc Sci Med. 2018;212:168-78.

10. Craig P, Katikireddi SV, Leyland A, Popham F. Natural experiments: an overview of methods, approaches, and contributions to public health intervention research. Annu Rev Public Health. 2017;38:39-56.

11. Clark D, Royer $\mathrm{H}$. The effect of education on adult mortality and health: evidence from Britain. Am Econ Rev. 2013:103:2087-120.

12. Gathmann C, Jürges H, Reinhold S. Compulsory schooling reforms, education and mortality in twentieth century Europe. Soc Sci Med. 2015; 127:74-82.

13. Davies NM, Dickson M, Davey Smith G, van den Berg GJ, Windmeijer F. The causal effects of education on health outcomes in the UK Biobank. Nat Hum Behav. 2018:2:117-25.

14. Oreopoulos P. Do dropouts drop out too soon? Wealth, health and happiness from compulsory schooling. J Public Econ. 2007:91:2213-29.

15. Chmielewski AK. An international comparison of achievement inequality in within- and between-school tracking systems. Am J Educ. 2014;120:293-324.

16. Timmins N. The five giants: a biography of the welfare state. Fully rev. and updated, paperback ed. London: HarperCollins; 2001

17. OECD. PISA 2012 results: what makes schools successful (volume IV): resources, Policies and Practices. OECD; 2013. https://doi.org/10.1787/ 9789264201156-en.

18. Kerckhoff AC. Going comprehensive in England and Wales: a study of uneven change. London; Portland: Woburn Press; 1996.

19. Paterson L, Pattie A, Deary IJ. Social class, gender and secondary education in Scotland in the 1950s. Oxf Rev Educ. 2011:37:383-401.

20. May T. The Conservative and Unionist Party Manifesto (2017), Forward together: our plan for a Stronger Britain and a Prosperous Future 2017. https://www.conservatives.com/manifesto.

21. Clark D. Selective Schools and Academic Achievement. BE J Econ Anal Policy. 2010;10. doi:10/cv659c.

22. Abdulkadiroglu A, Angrist J, Pathak P. The elite illusion: achievement effects at Boston and New York exam schools. Econometrica. 2014;82:137-96.

23. Clark D, Del Bono E. The long-run effects of attending an elite school: evidence from the United Kingdom. Am Econ J Appl Econ. 2016;8:150-76.

24. Dustmann C, Puhani PA, Schönberg U. The long-term effects of early track choice. Econ J. 2017;127:1348-80.

25. Phelan JC, Link BG, Tehranifar P. Social Conditions as Fundamental Causes of Health Inequalities: Theory, Evidence, and Policy Implications. J Health Soc Behav. 2010;51 1_suppl:S28-40.

26. Mackenbach JP, Kulhánová I, Bopp M, Deboosere P, Eikemo TA, Hoffmann R, et al. Variations in the relation between education and cause-specific mortality in 19 European populations: a test of the "fundamental causes" theory of social inequalities in health. Soc Sci Med. 2015;127:51-62.

27. Bann D, Hamer M, Parsons S, Ploubidis GB, Sullivan A. Does an elite education benefit health? Findings from the 1970 British Cohort Study. Int J Epidemiol. 2017:46(1):293-302. https://doi.org/10.1093/ije/dyw045.

28. Jones AM, Rice N, Rosa DP. Long-term effects of school quality on health and lifestyle: evidence from comprehensive schooling reforms in England. J Hum Cap. 2011;5:342-76.

29. Basu A, Jones AM, Dias PR. Heterogeneity in the impact of type of schooling on adult health and lifestyle. J Health Econ. 2018;57:1-14. 
30. Jones AM, Rice N, Rosa DP. Quality of schooling and inequality of opportunity in health. Empir Econ. 2012;42:369-94.

31. Leon DA, Lawlor DA, Clark H, Macintyre S. Cohort profile: The Aberdeen Children of the 1950s study. Int J Epidemiol. 2006;35:549-52.

32. Batty GD, Morton SMB, Campbell D, Clark H, Smith GD, Hall M, et al. The Aberdeen Children of the 1950s cohort study: background, methods and follow-up information on a new resource for the study of life course and intergenerational influences on health. Paediatr Perinat Epidemiol. 2004;18: 221-39.

33. Butler J, Black C, Craig P, Dibben C, Dundas R, Hilton Boon M, et al. Registered Report for the article: The long-term health effects of attending a selective school: a natural experiment. BMC Med. 2019. https://doi.org/10. 17605/OSF.IO/8GWQD.

34. Imbens GW, Lemieux T. Regression discontinuity designs: a guide to practice. J Econom. 2008;142:615-35.

35. Oldenburg CE, Moscoe E, Bärnighausen T. Regression discontinuity for causal effect estimation in epidemiology. Curr Epidemiol Rep. 2016;3:23341.

36. Cattaneo MD, Idrobo N, Titiunik R. A Practical Introduction to Regression Discontinuity Designs: Foundations. 1st edition. Cambridge University Press; 2019. https://doi.org/10.1017/9781108684606.

37. Paterson L, Pattie A, Deary IJ. Post-school education and social class destinations in Scotland in the 1950s. Longitud Life Course Stud. 2010;1. doi:10/ggc6kg.

38. Illsley R, Wilson F. The Aberdeen Child Development Study. In: Prospective Longitudinal Research, An Empirical Basis for the Primary Prevention of Psychosocial Disorders. p. 66-8.

39. ISD Services | Electronic Data Research and Innovation Service (eDRIS) | ISD Scotland. https://www.isdscotland.org/Products-and-Services/eDRIS/. Accessed 19 Nov 2019.

40. For the Alberta Kidney Disease Network, Tonelli M, Wiebe N, Fortin M, Guthrie B, Hemmelgarn BR, et al. Methods for identifying 30 chronic conditions: application to administrative data. BMC Med Inform Decis Mak. 2015;15. https://doi.org/10.1186/s12911-015-0155-5.

41. ICD-10: International statistical classification of diseases and related health problems. Geneva: World Health Organization; 2011.

42. Imbens $\mathrm{G}$, Kalyanaraman K. Optimal bandwidth choice for the regression discontinuity estimator. Rev Econ Stud. 2012;79:933-59.

43. Cappelleri JC, Darlington RB, Trochim WMK. Power analysis of cutoff-based randomized clinical trials. Eval Rev. 1994;18:141-52.

44. Kleiber C, Zeileis A. Applied econometrics with R. New York: Springer; 2008.

45. Jin Z, Liao W, Thoemmes F. rddapp: Regression Discontinuity Design Application. 2018.

46. McCrary J. Manipulation of the running variable in the regression discontinuity design: a density test. J Econom. 2008;142:698-714.

47. What Works Clearinghouse. Procedures handbook (Version 4.0). 2017.

48. Pastore C, Jones AM. Human capital consequences of missing outon a grammar school education. Health Econom Data Group HEDG Work Pap. 2019

\section{Publisher's Note}

Springer Nature remains neutral with regard to jurisdictional claims in published maps and institutional affiliations.

Ready to submit your research? Choose BMC and benefit from:

- fast, convenient online submission

- thorough peer review by experienced researchers in your field

- rapid publication on acceptance

- support for research data, including large and complex data types

- gold Open Access which fosters wider collaboration and increased citations

- maximum visibility for your research: over $100 \mathrm{M}$ website views per year

At $\mathrm{BMC}$, research is always in progress.

Learn more biomedcentral.com/submissions 